\title{
Increased 0-GIcNAc transferase in pancreas of rats with streptozotocin-induced diabetes
}

\author{
Y. Akimoto ${ }^{1,3}$, L.K. Kreppel ${ }^{2}$, H.Hirano ${ }^{3}$, G.W.Hart ${ }^{2}$ \\ ${ }^{1}$ Department of Biochemistry and Molecular Genetics Schools of Medicine and Dentistry, University of Alabama at Birmingham \\ Station, Alabama, USA \\ ${ }^{2}$ Department of Biological Chemistry, The Johns Hopkins University School of Medicine, Baltimore, Maryland, USA \\ ${ }^{3}$ Department of Anatomy, Kyorin University School of Medicine, Mitaka Tokyo, Japan
}

\section{Abstract}

Aims/hypothesis. Streptozotocin (STZ), a chemically reactive analogue of $N$-acetylglucosamine, induces necrosis of the beta cells, resulting in diabetes mellitus. Glucose-induced insulin resistance is mediated by increased activity of the hexosamine pathway. We aimed to examine the regulation of O-GlcNAc transferase expression and activity in the normal and streptozotocin diabetic pancreas.

Methods. Rats were made diabetic by an injection of streptozotocin $(65 \mathrm{mg} / \mathrm{kg})$. The expression of O-GlcNAc transferase protein was examined by immunoblot analysis. Activity of O-GlcNAc transferase was assayed by the incorporation of $\left[{ }^{3} \mathrm{H}\right] \mathrm{GlcNAc}$ into the synthetic peptide. Localization of O-GlcNAc transferase was done by immunohistochemistry. The change of O-GlcNAc modification of proteins was examined by immunoblot analysis.

Results. In the STZ-induced diabetic pancreas, a severe loss of beta cells was observed, whereas alpha cells had increased in number. The diabetic pancreas showed an increase in the expression of O-GlcNAc transferase at the protein level and the O-GlcNAc transferase activity in it was increased significantly $(p<0.05)$. An increase in the immunostaining intensity in the cytoplasm of islet beta cells was also observed in the diabetic pancreas, whereas exocrine cells and islet cells other than beta cells showed little change in immunostaining intensity. The pancreas of STZ-diabetic rats showed a 3.1-fold increase in total cellular O-GlcNAc-modified proteins.

Conclusion/interpretation. These findings indicate that O-GlcNAc transferase plays an important part in the modulation of O-GlcNAc concentrations in the pancreas and suggest that the increase in O-GlcNAc modification of the proteins correlates closely with diabetes. [Diabetologia (2000) 43: 1239-1247]

Keywords O-GlcNAc transferase, pancreas, streptozotocin, diabetes, immunohistochemistry, rat.
Received: 8 March 2000 and in revised form: 2 May 2000

Corresponding author: G.W. Hart, Department of Biological Chemistry, The Johns Hopkins University School of Medicine, Baltimore, Md. 21205, USA

Abbreviations: DAPI, 4',6'-Diamidine-2-phenylindole hydrochloride; dpm, disintegrations per min; GFAT, glutamine:fructose-6-phosphate amidotransferase; O-GlcNAc, serine(threonine)- $O$-linked $N$-acetylglucosamine; UPPGlcNAc, uridine diphospho- $N$-acetylglucosamine; OGTase, O-GlcNAc transferase; STZ, streptozotocin; HRP, horseradish peroxide; FITC, fluorescein isothiocyanate conjugate.
There are many nuclear and cytoplasmic proteins that are modified by a single $O$-linked $N$-acetylglucosamine (O-GlcNAc) moiety at serine or threonine residues $[1,2]$. We proposed that this $\mathrm{O}-\mathrm{GlcNAc}$ modification (termed O-GlcNAcylation) is a regulatory modification, analogous to phosphorylation, that is, capping of the potential phosphorylation sites $[1,3,4]$. O-GlcNAc transferase (OGTase: EC2.4.1), an enzyme responsible for O-GlcNAcylation of proteins, has been characterized [5] and its cDNA has been cloned $[5,6]$. O-GlcNAc transferase mRNA is highly expressed in the pancreas [6]. We previously showed that OGTase and O-GlcNAc are abundant in almost all pancreatic cells and are also abundant 
in the cells of the islets of Langerhans, especially in the alpha cells [7]. We speculate that O-GlcNAcylation of proteins by OGTase participates in the glucose-sensing mechanism in the pancreas.

The hexosamine biosynthesis pathway plays an important part in the induction of insulin resistance [8-14]. In this pathway, glutamine: fructose-6-phosphate amidotransferase (GFAT) has an integral role in the development of insulin resistance. The OGTase enzyme uses cytoplasmic uridine diphospho- $N$ acetylglucosamine (UDP-GlcNAc), which is synthesized in the hexosamine biosynthetic pathway [15, 16]. Animals with streptozotocin (STZ)-induced diabetes and hyperglycaemia show greatly increased concentrations of hexosamine metabolites including UDP-GlcNAc [11]. This increase in hexosamine biosynthesis could stimulate OGTase activity, inducing O-GlcNAc modification (O-GlcNAcylation) of proteins that are involved in the glucose transport system or in granule secretion. Recent kinetic analyses have confirmed that OGTase is exquisitely regulated by UDP-GlcNAc concentration across a broad range, from low micromolar to millimolar concentrations [17]. It is therefore likely that the effects of hyperglycaemia result from abnormal O-GlcNAcylation. In this study, the effects of streptozotocin (STZ) diabetes on the expression and activity of OGTase and on $\mathrm{O}-$ GlcNAcylation were investigated in the rat pancreas.

\section{Materials and methods}

Rat pancreas. The animal study was approved by the Johns Hopkins University School of Medicine Institutional Animal Care and Use Committee (IACUU). The Spraque-Dawley rats (CD strain, male, body weight 150-200 g) were obtained from the Charles River Laboratory (Wilmington, Mass., USA). Streptozotocin (STZ, $65 \mathrm{mg} / \mathrm{kg}$ body weight; Sigma, St. Louis, Mo., USA) was freshly dissolved in $50 \mathrm{mmol} / 1$ citrate buffer, $\mathrm{pH} 4.5$, and injected intraperitoneally into rats fasted overnight. Control rats received an injection of citrate buffer alone.

Antibodies. Rabbit polyclonal anti-OGTase antibody (AL-25, purified $\mathrm{IgG}$ ) was generated against a purified recombinant $110,000-\mathrm{M}_{\mathrm{r}}$ subunit of OGTase that was expressed in E. coli [5]. The AL-25 antibody recognizes both $110,000-M_{r}$ and $78,000-\mathrm{M}_{\mathrm{r}}$ subunits of OGTase and both subunits are immunoprecipitated by it. Moreover, OGTase enzymatic activity is precipitated by AL-25 [4]. Mouse monoclonal anti-O-GlcNAc antibody (HGAC 85) [18] was generously provided by Dr. N.S. Greenspan (Case Western Reserve University, Cleveland, Ohio, USA). We obtained $\mathrm{Cy} 3$ or horseradish peroxide (HRP)-conjugated donkey anti-rabbit IgG antibody and fluorescein isothiocyanate conjugate (FITC) or alkaline phosphatase (ALPase)-conjugated donkey anti-mouse IgG from Jackson Immunoresearch (West Grove, Pa., USA). Mouse monoclonal anti-insulin antibody and anti-glucagon antibody were purchased from Sigma, and rabbit polyclonal anti-insulin and glucagon antibodies were obtained from Novocastra Laboratories (Newcastle, UK).
Western blot analysis. Crude protein extracts were prepared from pancreata dissected from either normal or STZ-diabetic Sprague-Dawley rats (male, body weight 150-200 g). The pancreas was homogenized in a homogenization buffer $[20 \mathrm{mmol} / 1$ TRIS- $\mathrm{HCl}$ (pH 7.4), $5 \mathrm{mmol} / \mathrm{l}$ EDTA, $5 \mathrm{mmol} / \mathrm{l}$ EGTA, $1 \mathrm{mmol} / \mathrm{l}$ dithiothreitol (DTT), $2 \mathrm{mmol} / \mathrm{l}$ phenylmethylsulphonyl fluoride (PMSF), protease inhibitor cocktail 1 and 2 (1:1000 dilution)] [19]. When the O-GlcNAc modification of proteins was examined, $O$-(2-acetamido-2-deoxy-D-glucopyranosylidene)-amino- $N$-phenylcarbamate [PUGNAc, a generous gift from Oxford GlycoSciences (Oxford, UK)] was added to the homogenization buffer (final concentration, $0.1 \mathrm{mmol} / \mathrm{l}$ ) to inhibit the activity of endogenous O-GlcNAc- $N$-acetylglucosaminidase (O-GlcNAcase), the enzyme responsible for the removal of O-GlcNAc from proteins [20, 21]. The proteins were separated by SDS-PAGE and transferred to polyvinylidene difluoride (PVDF) membranes. Purified rabbit polyclonal IgG AL-25 (1:5000) or mouse monoclonal anti-O-GlcNAc antibody (HGAC 85, 1:1000 dilution) was used as a primary antibody and anti-rabbit or anti-mouse IgG coupled to horseradish peroxidase (Amersham Pharmacia, Piscataway, N. J., USA), as the secondary antibody (1:20,000 dilution). The horseradish peroxidase activity was detected by enhanced chemiluminescence (ECL) as described by the manufacturer (Amersham). The intensity of protein bands of normal and diabetic rat pancreas was quantified by scanning densitometry.

OGTase activity assay. Normal and STZ-diabetic rat liver, eye, heart, spleen and pancreas were homogenized in a Dounce homogenizer with buffer [10 mmol/l TRIS-HCl ( $\mathrm{pH} 7.5$ ), $10 \mathrm{mmol} / 1 \mathrm{MgCl}_{2}, 1 \mathrm{mmol} / \mathrm{l} \mathrm{EDTA}$ and $\left.1 \mathrm{mmol} / \mathrm{l} \mathrm{PMSF}\right]$ and sonicated. The insoluble material was pelleted by centrifugation at $27,500 \mathrm{~g}$ for $30 \mathrm{~min}$ and discarded. The supernatant was made $30 \%$ saturated with ammonium sulphate. The supernatants were allowed to sit overnight on ice, and the resulting precipitate was collected by centrifugation at $12,000 \mathrm{~g}$ for $20 \mathrm{~min}$. The supernatants were discarded, and the pellets were resuspended in buffer $(20 \mathrm{mmol} / \mathrm{l}$ TRIS-HCl, $\mathrm{pH} 7.8,20 \%$ glycerol). The insoluble material was removed by centrifugation at $12,000 \mathrm{~g}$ for $15 \mathrm{~min}$, and the final supernatant was used as the source of enzyme.

The OGTase assays were done as described previously [22]. The reaction mixture for the standard assay contained $50 \mathrm{mmol} / \mathrm{l}$ sodium cacodylate, $(\mathrm{pH} 6.0), 150 \mu \mathrm{g}$ of the synthetic peptide YSDSPSTST, $2.5 \mathrm{mmol} / 1$ 5'-adenosine monophosphate and $18.5 \mathrm{kBq}$ of UDP-[6- $\left.{ }^{3} \mathrm{H}\right] \mathrm{GlcNAc}$. The reaction was started by the addition of enzyme and continued for $30 \mathrm{~min}$ at $20^{\circ} \mathrm{C}$. The reaction was stopped by the addition of $50 \mathrm{mmol} / \mathrm{l}$ formic acid and then the mixture was loaded onto a $0.5-\mathrm{ml}$ SP-Sephadex (SP-C25-120, Sigma) column equilibrated with the same buffer. The column was washed with $50 \mathrm{mmol} / \mathrm{l}$ formic acid and the peptides were eluted with $0.5 \mathrm{~mol} / \mathrm{l} \mathrm{NaCl}$. Incorporation of $\left[{ }^{3} \mathrm{H}\right] \mathrm{GlcNAc}$ into the peptide was quantified by liquid scintillation spectrophotometry.

Immunostaining for light microscopic observation. Specimens were fixed in $4 \%$ formaldehyde in $0.1 \mathrm{~mol} / \mathrm{l}$ phosphate buffer (pH 7.3) for $1 \mathrm{~h}$ at $4{ }^{\circ} \mathrm{C}$, immersed in $2.3 \mathrm{~mol} / 1$ sucrose-phosphate-buffered saline (PBS) for $1 \mathrm{~h}$ at $4{ }^{\circ} \mathrm{C}$, and then frozen with liquid nitrogen. Semithin-frozen sections of 1-2 $\mu \mathrm{m}$ thickness were cut, washed with PBS and treated for 10 min with $1 \%$ bovine serum albumin (BSA) in PBS. The sections were then incubated with AL-25 (1:250) or with pre-immune rabbit IgG (1:250) for $1 \mathrm{~h}$ at room temperature, washed with PBS and subsequently incubated for $1 \mathrm{~h}$ with $\mathrm{Cy} 3$-conjugated donkey anti-rabbit IgG antibody (1:1000) (Jackson Immunoresearch). The sections were then incubated with the mouse 
A

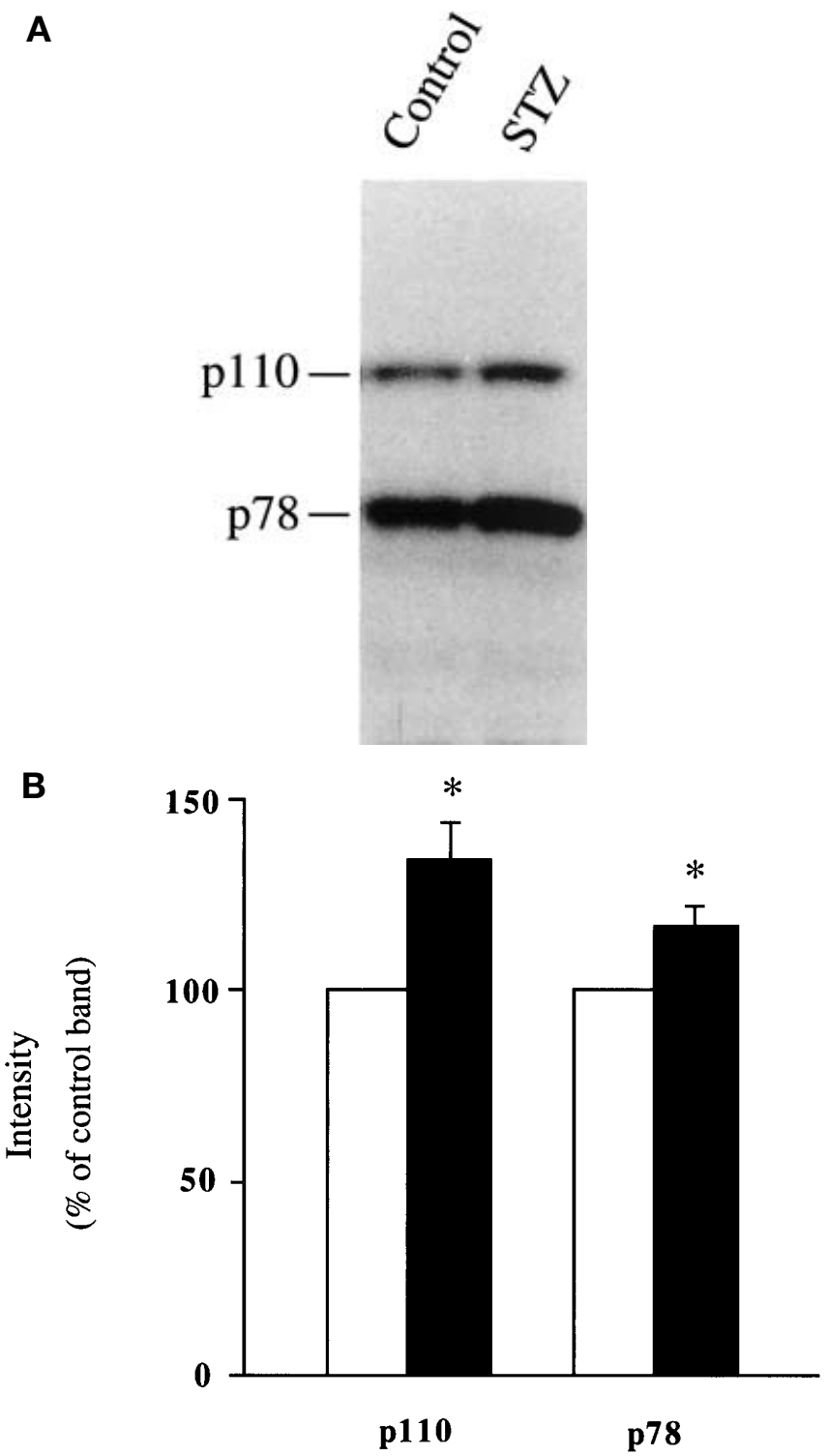

Fig.1A, B. Immunoblot analysis of normal and streptozotocin-diabetic pancreata lysate by use of anti-OGTase antibody. A The normal or STZ-diabetic pancreas was lysed. The same amount of protein is loaded per track in the normal and STZdiabetic pancreas lysates and electrophoresed on a $7.5 \%$ polyacrylamide gel and immunoblotted with AL-25. The positions of the p110 and p78 subunits of OGTase are indicated. The figure is representative of three experiments. B The intensity of bands obtained from homogenates of normal $(\square)$ and diabetic (ם) rat pancreas was quantified by scanning densitometry. In the STZ-diabetic pancreas, the intensity of both p110 and p78 was significantly increased over the normal value. The intensity of each band (p110 and p78) was expressed as the mean percentages of the control \pm standard error of the band intensity ratio. $* p<0.05$ vs control. Experiments were done in triplicate

monoclonal anti-insulin (1:1000) or anti-glucagon (1:1000) antibodies (Sigma) for $1 \mathrm{~h}$ at room temperature, washed with PBS and incubated for $1 \mathrm{~h}$ with FITC-conjugated donkey anti mouse IgG (Jackson Immunoresearch). Nuclei were stained with 4',6-diamidine-2-phenylindole hydrochloride (DAPI, Boehringer Mannheim, Indianapolis, Ind., USA). After a wash with PBS, the specimens were mounted in $90 \%$ glycerol-0.1 mol/l TRIS-HCl buffer ( $\mathrm{pH} 8.5$ ) containing $0.5 \mathrm{mmol} / \mathrm{l}$ p-phenylene diamine, which prevents fading of fluorescence during microscopic examination, and observed under a Leica microscope equipped with an epifluorescence system and chilled 3CCD colour camera (C5810, Hamamatsu Photonics Systems, Bridgewater, N.J., USA). Quantification of immunostaining intensity in nuclear and cytoplasmic regions was done by use of the public domain NIH image program (developed at the National Health Institutes, Bethesda, Md., USA). The results (means \pm SEM) represent duplicate measurements made in six separate experiments. The terms increase and decrease are applied only when the results were statistically significant ( $t$ test, $p<0.05$ ).

\section{Results}

Immunoblot analysis of OGTase in the normal and diabetic pancreas with anti-OGTase antibody $(A L-25)$. The AL-25 antibody recognized both the $110,000-\mathrm{M}_{\mathrm{r}}$ and 78,000- $\mathrm{M}_{\mathrm{r}}$ subunits of OGTase (Fig.1). The intensity of the $78,000-\mathrm{M}_{\mathrm{r}}$ band was stronger than that of the $110,000-\mathrm{M}_{\mathrm{r}}$ one. The density of protein bands obtained with homogenates of normal and diabetic rat pancreas was quantified by scanning densitometry (Fig.1). The amount of both $110,000-\mathrm{M}_{\mathrm{r}}$ alpha subunit (p110) and 78,000- $\mathrm{M}_{\mathrm{r}}$ beta subunit (p78) was significantly increased in the STZ diabetic pancreas $(p<0.05)$, because the same amount of protein is loaded per track.

Assay for OGTase activity in normal and STZ-diabetic rat pancreas. Rats were made diabetic using standard procedures, as follows. On days 5-7 after injection of STZ, the serum glucose concentration was assayed by the hexokinase and glucose-6-phosphate dehydrogenase method (Sigma). The rats were then killed to obtain their pancreatic tissue. Plasma glucose was increased $(p<0.001)$ in diabetic animals $(25.65 \pm 1.47 \mathrm{mmol} / \mathrm{l}$, means $\pm \mathrm{SEM}, n=8)$ compared with controls $(5.42 \pm 1.34 \mathrm{mmol} / \mathrm{l}, n=6)$. To examine the effect of STZ diabetes on the OGTase activity of pancreas and other tissues, the OGTase activities in pancreas, liver, heart, spleen and eye were assayed. The $30 \%$ ammonium sulphate cytosolic pellets were assayed for enzymatic activity. There was no significant difference in the OGTase activity between normal $[366.4 \pm 24.5,115 \pm 11.2,224.1 \pm 13.9$ means \pm SEM disintegrations per min $(\mathrm{dpm}) / \mu \mathrm{g}$ protein] and STZ-diabetic $(336.7 \pm 20.3,116.8 \pm 5.1,208.6 \pm 14.1$ $\mathrm{dpm} / \mu \mathrm{g}$ protein) rat liver, heart and spleen, respectively (Fig.2). The OGTase activity of the diabetic rat pancreas $(535.3 \pm 17.6 \mathrm{dpm} / \mu \mathrm{g}$ protein $)$ was, however, higher $(p<0.05)$ than that of the normal pancreas $(199.3 \pm 9.1 \mathrm{dpm} / \mu \mathrm{g}$ protein $)$. The enzyme activity of the diabetic rat eye $(134.55 \pm 19.6 \mathrm{dpm} / \mu \mathrm{g}$ protein) was also higher $(p<0.05)$ than that of a normal eye $(55.98 \pm 14.6 \mathrm{dpm} / \mu \mathrm{g}$ protein $)$. 


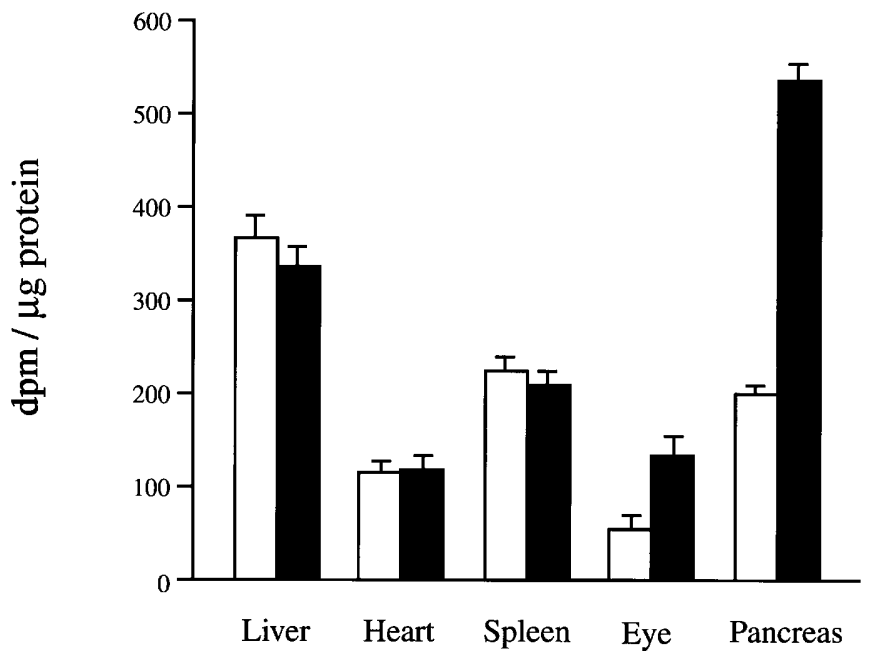

Fig. 2. OGTase activity (dpm/ $\mu$ g protein) in normal $(\square)$ and diabetic ( $\square$ ) rat liver, heart, spleen, eye and pancreas. Data represent the means $\pm \operatorname{SEM}$. $(n=6)$

Changes in immunostaining of OGT in STZ diabetic pancreas. The distribution of OGTase in the pancreas was examined by immunofluorescence microscopy (Figs. 3, 4). The immunofluorescence intensity of nuclear and cytoplasmic regions of alpha and beta cells was quantified in the control and STZ diabetic pancreas (Fig.5). The multiple staining method showed that the alpha cells of Langerhans islets of normal pancreas were enriched in OGTase, that is, intense staining was observed in the cytoplasm as well as in the nucleus of the alpha cells (Fig. 4). In the beta cells, intense staining was observed in the nucleus, whereas the cytoplasm was diffusely and weakly stained (Fig. 4). In the exocrine acinar cells, nuclei and the region containing zymogen granules were intensely stained with AL-25 (data not shown). In the Langerhans islets of STZ-diabetic pancreas, a significant decrease in the number of beta cells due to beta-cell necrosis was observed, whereas alpha cells increased in number (Fig.4). The immunostaining in the cytoplasm of the beta cell of the STZ-diabetic rat increased in intensity, whereas the nucleus showed little change (Fig. 5). No change in the localization or immunostaining intensity of OGTase was, however, observed in alpha cells (Figs. 4, 5) or acinar cells (data not shown). In the control experiment in which the primary antibody was omitted or replaced with preimmune rabbit IgG instead of AL-25, no positive staining was observed (data not shown).

Effect of STZ diabetes on the O-GlcNAc modification of proteins in the pancreas. To study the effect of STZ diabetes on the O-GlcNAc modification, we extracted total proteins from normal and STZ-diabetic pancreata. Proteins were separated by SDS-gel electrophoresis and analysed by Western blotting with monoclonal anti-O-GlcNAc antibody (HGAC 85).
Proteins extracted from the normal pancreata had a lower O-GlcNAc content (Fig. 6). In contrast, at least six major proteins [molecular weights $\left(\mathrm{M}_{\mathrm{r}}\right)$ of 46,000 , $37,000,31,000,15,000,12,000,9300]$ from the STZ-diabetic pancreata showed an increase in the amount of O-GlcNAc modification [The increases were (in folds) $3.13,1.25,1.32,6.32,4.45,2.51$ for each of the above proteins respectively, with an average increase of 3.1 fold].

\section{Discussion}

Because we showed previously that OGTase and OGlcNAc are present abundantly both in the exocrine acinar cells and endocrine islet cells of the pancreas [7], as a next step, we examined the expression and the activity of the OGTase in the pancreas and the O-GlcNAcylation of total pancreatic proteins. In this study, an increase in OGTase expression and activity was found in the STZ-diabetic pancreas. The amount of enzyme activity was, however, not linearly dependent upon the amount of OGTase proteins, as we previously observed in various tissues [5]. This indicates that additional factors regulate the activity of OGTase [17]. Previous immunohistochemical studies of OGTase distribution in the pancreas showed a uniquely concentrated distribution of the O-GlcNAc modification [7]. Its localization both in nucleus and cytoplasm of all pancreatic cells, especially in the nucleus, suggests that it has a fundamental cellular function. In the nucleus OGTase catalyses the O-GlcNAcylation of many nuclear proteins, such as nuclear pore proteins, RNA polymerase II, transcription factors, c-myc oncoprotein, p53 tumour suppressor and oestrogen receptor [2,23]. Another characteristic distribution of OGTase is its rich cytoplasmic localization in the exocrine acinar cells and islet cells. An immunoelectron microscopic study showed that in the exocrine acinar cells and islet cells OGT was localized around the secretory granules [7], suggesting that OGTase is involved in the process of secretion of granules. In this study a statistically significant increase in immunostaining intensity of OGTase was detected in the cytoplasm of islet beta cells in the STZ-diabetic pancreas whereas no change was observed in the exocrine acinar cells and other islets cells. The capacity to secrete insulin in STZ-diabetic rats is significantly reduced from the control in the isolated islets [24]. The OGTase enzyme could regulate granular secretion of beta cells in the STZ-diabetic pancreas by catalysing the O-GlcNAcylation of cytoskeletal proteins such as microtubule-associated proteins which are involved in the secretion or transport of granules/vesicles [25-29] and are heavily OGlcNAcylated [30-33].

It has been shown that the hexosamine biosynthesis pathway mediates the glucose-induced desensiti- 

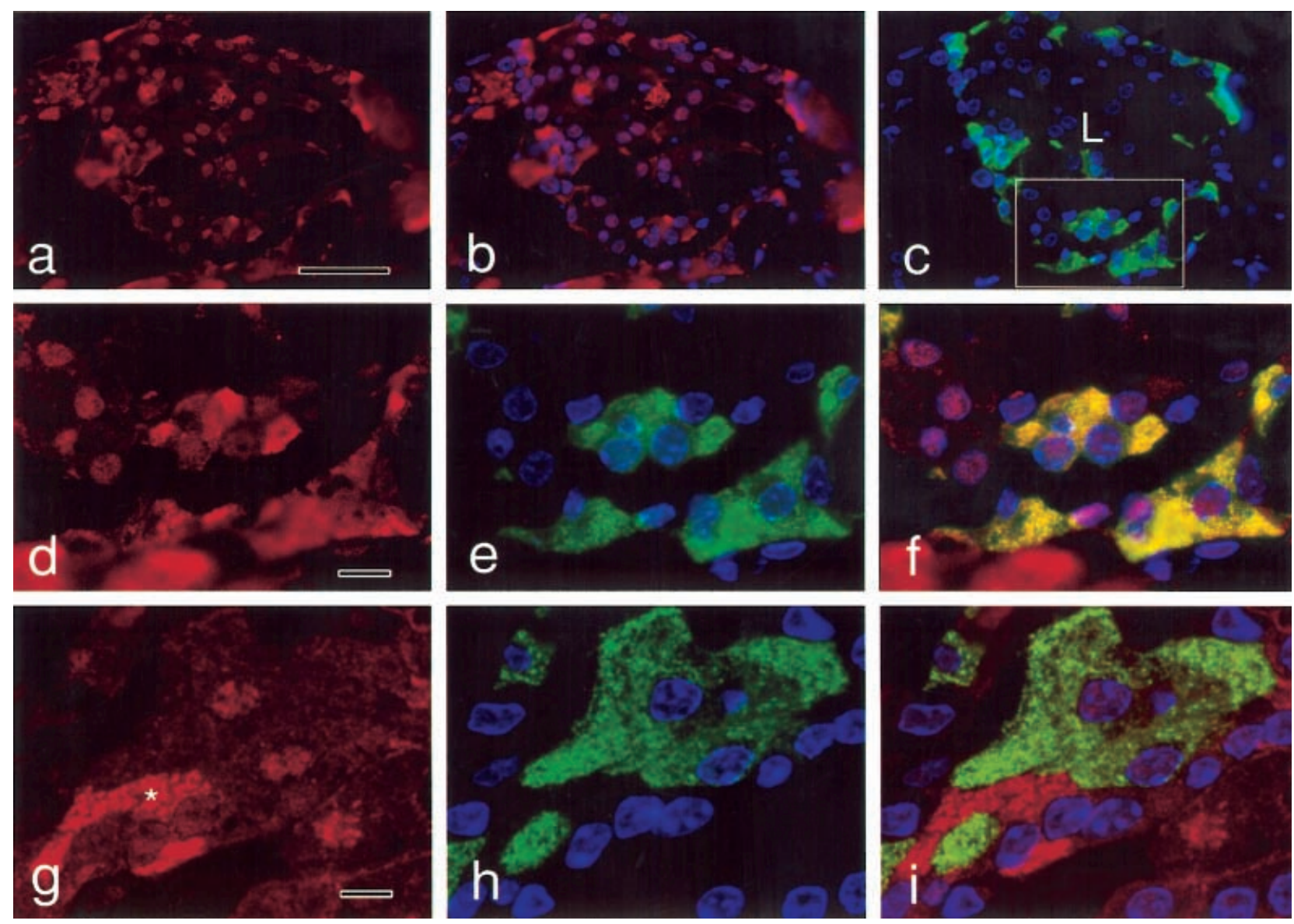

Fig.3a-i. Immunofluorescent distribution of anti-OGTase, anti-glucagon and anti-insulin reactivity in the Langerhans islet of normal rat pancreas. Pancreas was fixed with $4 \%$ paraformaldehyde. Semithin frozen sections reacted with rabbit polyclonal anti-OGTase antibody (AL-25) and then with Cy3-donkey anti-rabbit IgG. The sections were subsequently incubated with mouse monoclonal anti-glucagon or insulin antibody, then with FITC-donkey anti-mouse IgG. Nuclei were stained with DAPI (blue). a-c Same optical field. a Distribution of AL-25 reactivity (red). b Double-exposure image for AL-25 and nucleus (blue). c Double-exposure image for glucagon (green) and nucleus (blue). The alpha cells are preferentially localized at the periphery of the Langerhans islet (L). d-f Same optical field. d Enlargement of a. e Enlargement of rectangle in c. f Tripleexposure image for AL-25, glucagon and nuclei. Intense signals are observed in both the cytoplasm and nucleus of the alpha cells. g-i Same optical field. g Distribution of AL-25 reactivity (red) in another optical field of an islet. h Double-exposure image for insulin (green) and nuclei (blue). i Triple-exposure image for AL-25, insulin and nuclei. Intense signals are observed in the nuclei of beta cells and in the cytoplasm of the cells that are thought to be alpha cells (asterisk). Bar in a, $50 \mu \mathrm{m}$. Bars in d and $\mathbf{g}, 10 \mu \mathrm{m}$

zation of the glucose transport system and induces insulin resistance [8-14]. The glutamine:fructose-6phosphate amidotransferase (GFAT), which is a rate-limiting enzyme of the hexosamine pathway, plays an integral part in insulin resistance. Its activity is regulated coordinately by insulin, glucose and glutamine [34]. Overexpression of GFAT in the transgenic mouse induces insulin resistance [35] and inhibits glucose transporter 4 (GLUT-4) translocation from intracellular vesicles to the plasma membrane [36]. Diabetes induced by STZ increases the concentration of UDP-hexosamine in rat skeletal muscle [11]. The UDPGIcNAc is a final product of hexosamine synthesis. In the O-GlcNAcylation of proteins, OGTase uses cytoplasmic UDPGlcNAc that is synthesized in the hexosamine biosynthetic pathway $[15,16]$ and OGTase's activity is tightly regulated by the amounts of O-GlcNAc over the entire physiologic range of the sugar donor's concentration within cells [17]. Here we show that the OGTase activity in the pancreas and eye is increased in STZ-diabetic rats. Using anti-O-GlcNAc antibody for immunoblotting, we found that STZ-diabetic rats showed a 3.1-fold increase in total O-GlcNAcylated proteins in their pancreata. Several protein bands from STZ-diabetic rat pancreata had greater staining for O-GlcNAc than the corresponding bands from control pancreata. This increase in the staining for O-GlcNAc could be ascribed to: (1) increased O-GlcNAc-modification of pre-existing proteins, (2) increased synthesis of O-GlcNAcylated-protein, (3) the increased proportion of alpha cells or exocrine cells in the STZ-diabetic rat pancreas or (4) all 

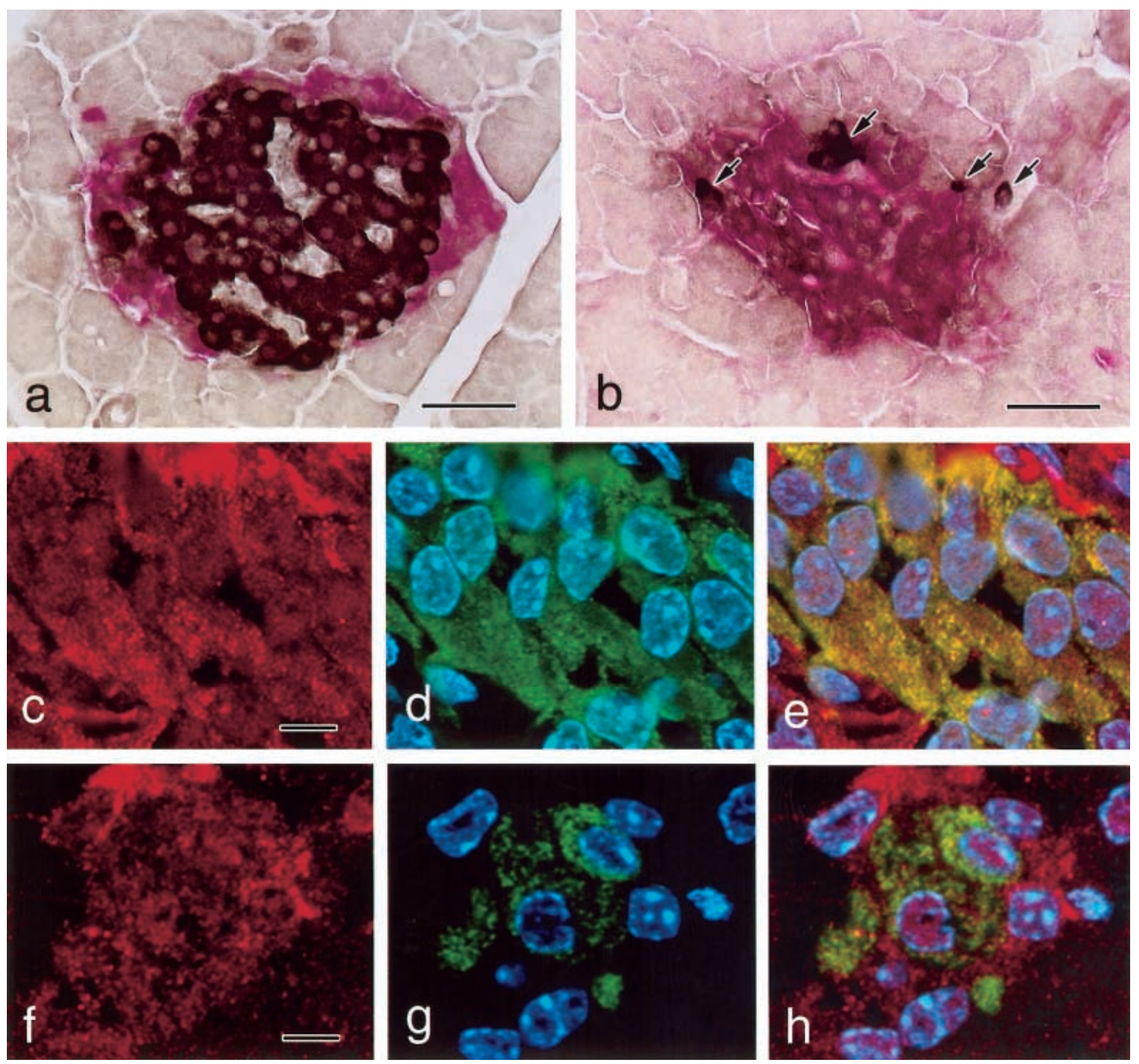

Fig. 4a-h. Immunofluorescent distribution of anti-OGTase, anti-glucagon and anti-insulin reactivities in the Langerhans islets of STZ-diabetic rat pancreas. a,b Pancreas was fixed with $4 \%$ paraformaldehyde. Paraffin sections reacted with mouse monoclonal anti-insulin antibody and then with HRP-labelled secondary antibody. The signal (dark brown) of insulin was detected with 3,3'-diaminobenzidine (DAB) in the presence of $\mathrm{NiCl}_{2}$. After the DAB reaction, the sections were incubated with rabbit polyclonal anti-glucagon antibody and then with alkaline phosphatase-labelled secondary antibody. The signal (red) of glucagon was detected with fast red. a In the islet of normal pancreas, the beta cells are located centrally, whereas the alpha cells lie peripherally. b In the islet of the STZ-diabetic pancreas, beta cells (arrows) are decreased in number, whereas alpha cells have increased in number. $\mathbf{c}-\mathbf{h}$ The immunostaining was done as in Fig. 3. c-e Same optical field. c Distribution of AL-25 reactivity (red) in the alpha cells. d Distribution of glucagon reactivity (green) in the alpha cell. e Triple-exposure image for AL-25, glucagon and nuclei. f-h Same optical field. f Distribution of AL-25 reactivity (red). g Distribution of insulin reaction (green). h Triple-exposure image for AL-25, insulin and nuclei. Bars in $\mathbf{a}$ and $\mathbf{b}, 50 \mu \mathrm{m}$. Bars in $\mathbf{c}$ and $\mathbf{f}, 10 \mu \mathrm{m}$ three. Enhancement of OGTase activity in the diabetic pancreas implies an important role for OGTase in diabetes. This heightened activity could induce an increase in the O-GlcNAcylation of proteins that are involved in granule secretion and vesicle translocation. We posit that in the pancreas, O-GlcNAcylation of proteins by OGTase are involved in the normal glucose-sensing mechanism and in the peripheral tissues, OGTase is involved in the desensitization of the glucose uptake system by mediating O-GlcNAcylation of cytoskeletal proteins. These are the proteins that regulate the glucose transporter translocation from intracellular vesicle to the plasma membrane.

In our study no significant change of OGTase activity was observed in the liver, heart and spleen of STZ-diabetic rats, but OGTase activity increased in the eye and pancreas. In the liver the GFAT activities are similar in $o b / o b$ mice and controls [13] but de- 


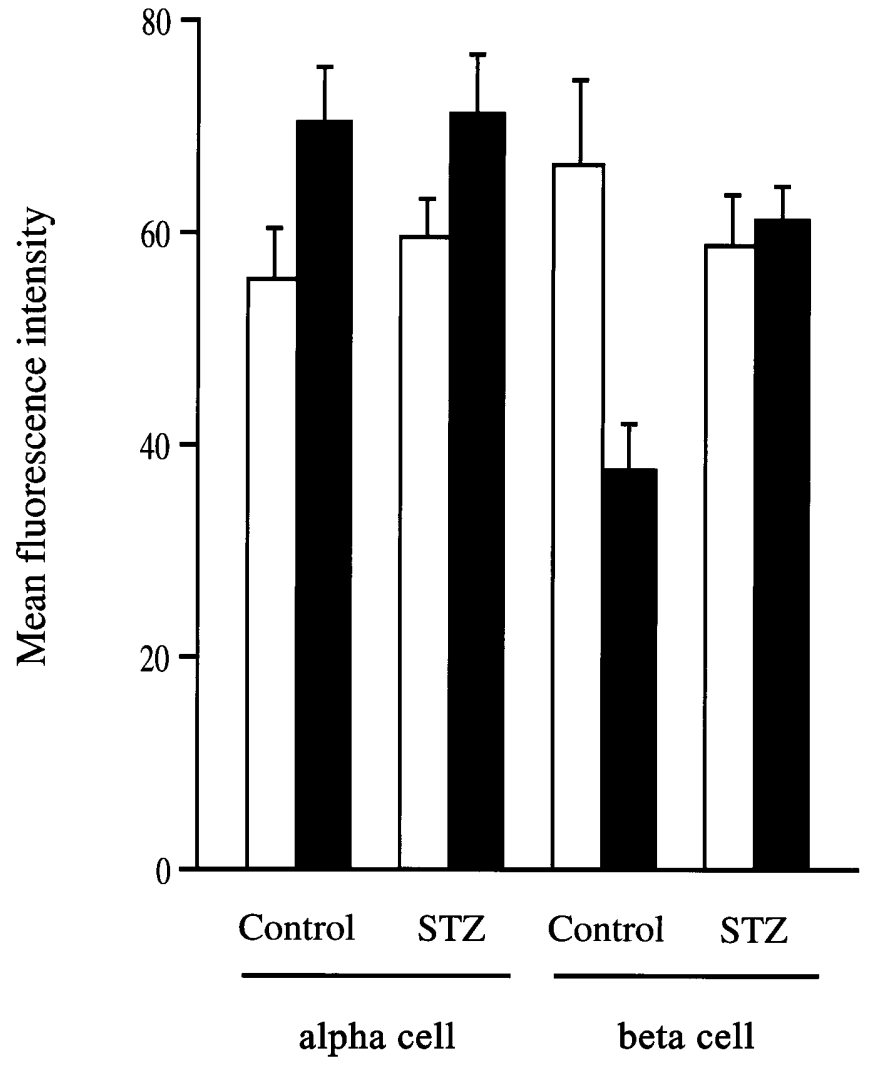

Fig.5. Effect of STZ diabetes on the OGTase immunoreactivity of islet cells. Graphical quantification of the OGTase immunoreactivity in nucleus and cytoplasm of alpha and beta cells. Symbols: $(\square)$ nucleus, ( $\square)$ cytoplasm. In the alpha cells, there was little change in the immunoreactivity. STZ diabetes resulted in an increase in immunoreactivity in the cytoplasm of beta cells. Data represent the means \pm SEM in six independent experiments

crease in STZ-diabetic rats [11]. The OGTase activity seems to be differently regulated in each tissue. Each tissue consists of heterogeneous cells, therefore OGTase activity could be different in each cell type and respond differently to diabetes [11]. The expression of tissue-specific forms of OGTase is one mechanism by which the activity or substrate specificity of the enzyme could be regulated [5].

Streptozotocin is a glucosamine analogue that specifically destroys islet beta cells $[37,38]$. In the STZdiabetic pancreas, necrosis of beta cells occurs and severe degranulation is observed in the beta cells [39-41]. Beta cells do not, however, completely necrotize. Limited proliferation derived from pre-existing precursor beta cells occurs about 4 days after STZ is given to rats [42]. The beta cells or beta-cell lines that express glucose transporter 2 (GLUT-2) show enhanced transport of STZ [43]. Meanwhile, kidney, liver and small intestine, all of which also express GLUT-2 [44], are less susceptible to STZ. Streptozotocin has been shown to induce DNA strand breaks or free radicals [45-48]. The mecha- a
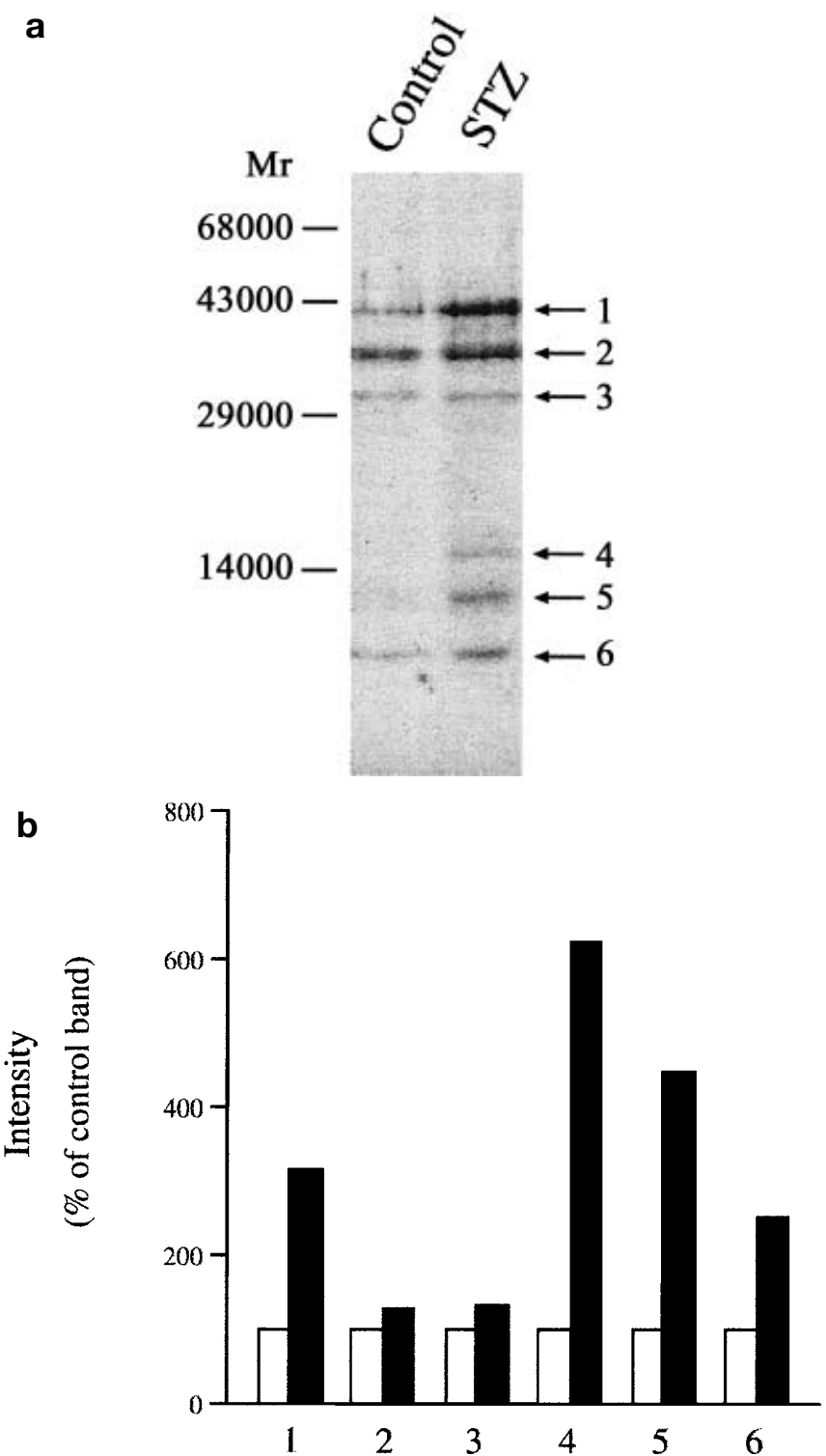

Fig. 6a, b. Effect of STZ diabetes on the O-GlcNAc modification of proteins in pancreas. a The total proteins from control and STZ diabetic pancreas were separated by SDS gel electrophoresis and analysed by western blotting using monoclonal anti-O-GlcNAc antibody (HGAC85 as a probe). b The intensity of bands (1-6 in a) was measured by a scanning densitometer. The intensity of each band is plotted as the percentage of the intensity of the corresponding control band. The figure is representative of three similar experiments. Symbols: $(\square)$ control, (ם) STZ

nism of STZ-induced beta-cell toxicity is, however, not clearly understood [46, 49-52]. Because STZ is a weak inhibitor of O-GlcNAcase $\left(\mathrm{IC}_{50}=\sim 2.5 \mathrm{mmol} / \mathrm{l}\right.$, Parker and Hart, unpublished), the enzyme responsible for O-GlcNAc removal, it has been proposed that inhibition of O-GlcNAcase induces the accumulation of O-GlcNAcylated proteins, thus contributing to selective beta cell apoptosis by STZ [53, 54]. Our data indicates that OGTase plays a part in the modulation of O-GlcNAc concentrations in the beta cells 
of STZ-diabetic pancreas. Recently, it was shown that STZ and glucose increase the O-GlcNAcylation of beta-cell proteins, especially $135,000-\mathrm{M}_{\mathrm{r}}$ protein [53, $55,56]$. In the absence of hyperglycaemia, STZ itself does not alter the O-GlcNAcylation in beta cells [56]. Although glucose induces the rapid and reversible accumulation of O-GlcNAc in beta cells, STZ-induced accumulation of O-GlcNAc is irreversible even after normoglycaemia is re-established by insulin infusion [56]. This indicates that the removal of O-GlcNAc modification was blocked by STZ. Furthermore, transgenic mice in which GFAT antisense is expressed to impair glucosamine synthesis are resistant to the diabetogenic effect of STZ [56]. Thus, the O-GlcNAcylation of proteins in the beta cells could play a part in the development of diabetes induced by STZ and glucose. Of note STZ-induced accumulation of O-GlcNAc in the beta cells is implicated in beta cell apoptosis. Our study showed that more O-GlcNAcylated proteins, measured in total pancreatic proteins, are present in STZ-diabetic rats than in control rats $[55,56]$ and that the amount of the OGTase is stimulated in STZ-diabetic rats. Thus we think that STZ has effects not only on the islet cells but also on the exocrine cells.

Acknowledgements. We thank B. J. Hart for peptide synthesis, R. Marchase, J.E. Kudlow and all the members of the Hart Laboratory for helpful discussions. This work was supported in part by the Juvenile Diabetes Foundation and Fifty 50 Foods Inc., by NIH Grant HD13563 awarded to G. W. Hart and by a gift from Oxford Glycosystems Inc. We also wish to express our appreciation to M. Fukuda, S. Matsubara, M. Kanai and S. Shibata (Laboratory for Electron Microscopy and Department of Anatomy, Kyorin University School of Medicine) for their technical assistance. This work was supported in part by grants-in-aid for scientific research from the Ministry of Education, Science, Sports and Culture of Japan and from the Kazato Research Foundation. G. W. Hart is on the Scientific Advisory Board of Oxford GlycoSciences and was a consultant to Monsanto Corporation.

\section{References}

1. Hart GW, Haltiwanger RS, Holt GD, Kelly WG (1989) Glycosylation in the nucleus and cytoplasm. Annu Rev Biochem 58: 841-874

2. Snow DM, Hart GW (1998) Nuclear and cytoplasmic glycosylation. Int Rev Cytol 181: 43-74

3. Kearse KP, Hart GW (1991) Lymphocyte activation induces rapid changes in nuclear and cytoplasmic glycoproteins. Proc Natl Acad Sci USA 88: 1701-1705

4. Hart GH, Kreppel LK, Comer FI et al. (1996) O-GlcNAcylation of key nuclear and cytoskeletal proteins: reciprocity with $\mathrm{O}$-phosphorylation and putative roles in protein multimerization. Glycobiology 6: 711-716

5. Kreppel LK, Blomberg MA, Hart GW (1997) Dynamic glycosylation of nuclear and cytoplasmic proteins. cloning and Characterization of a unique O-GlcNAc transferase with multiple tetratricopeptide repeats. J Biol Chem 272: 9308-9315
6. Lubas WA, Frank DW, Krause M, Hanover JA (1997) OLinked GlcNAc transferase is a conserved nucleocytoplasmic protein containing tetratricopeptide repeats. J Biol Chem 272: 9316-9324

7. Akimoto Y, Kreppel LK, Hirano H, Hart GW (1999) Localization of the O-GlcNAc transferase in rat pancreas. Diabetes 48: 2407-2413

8. Marshall S, Bacote V, Traxinger RR (1991) Discovery of a metabolic pathway mediating glucose-induced desensitization of the glucose transport system. J Biol Chem 266: 4706-4712

9. Baron AD, Zhu J-S, Zhu J-H, Weldon H, Maianu L, Garvey WT (1995) Glucosamine induces insulin resistance in vivo by affecting GLUT4 translocation in skeletal muscle. Implications for glucose toxicity. J Clin Invest 96: 2792-2801

10. Rossetti L, Hawkins M, Gindi J, Barzilai N (1995) In vivo glucosamine infusion induces insulin resistance in normoglycaemic but not in hyperglycemic conscious rats. J Clin Invest 96: 132-140

11. Robinson KA, Weinstein ML, Lindenmayer GE, Buse MG (1995) Effects of diabetes and hyperglycaemia on the hexosamine synthesis pathway in rat muscle and liver. Diabetes 44: 1438-1446

12. McClain DA, Crook ED (1996) Hexosamines and insulin resistance. Diabetes 45: 1003-1009

13. Buse MG, Robinson KA, Gettys T W, McMahon EG, Gulve EA (1997) Increased activity of the hexosamine synthesis pathway in muscles of insulin-resistant ob/ob mice. Am J Physiol: 1080-1088

14. Thomson MJ, Williams MG, Frost SC (1997) Development of insulin resistance in 3T3-L1 adipocytes. J Biol Chem 272: 7759-7764

15. Hawkins M, Angelov I, Liu R, Barzilai N, Rossetti L (1997) The tissue concentration of UDP-N-acetylglucosamine modulates the stimulatory effect of insulin on skeletal muscle glucose uptake. J Biol Chem 272: 4889-4895

16. Yki-Järvinen H, Vogt C, Iozzo CV et al. (1997) UDP-Nacetylglucosamine transferase and glutamine: fructose 6phosphate amidotransferase activities in insulin-sensitive tissues. Diabetologia 40: 76-81

17. Kreppel LK, Hart GW (1999) Regulation of a cytosolic and nuclear O-GlcNAc transferase: role of the tetratricopeptide repeats. J Biol Chem 274: 32015-32022

18. Turner JR, Tartakoff AM, Greenspan NS (1990) Cytologic assessment of nuclear and cytoplasmic O-linked N-acetylglucosamine distribution by using anti-streptococcal monoclonal antibodies. Proc Natl Acad Sci USA 87: 5608-5612

19. Roquemore EP, Chou TY, Hart GW (1994) Detection of O-Linked N-Acetylglucosamine (O-GlcNAc) on Cytoplasmic and Nuclear Proteins. Methods Enzymol 230: 443-460

20. Dong DL-Y, Hart GW (1994) Purification and characterization of an O-GlcNAc selective $\mathrm{N}$-acetyl- $\beta$-D-glucosaminidase from rat spleen cytosol. J Biol Chem 269: 19321-19330

21. Haltiwanger RS, Grove K, Philipsberg GA (1998) Modulation of O-linked $\mathrm{N}$-acetylglucosamine levels on nuclear and cytoplasmic proteins in vivo using the peptide O-GlcNAc$\beta$-N-acetylglucosaminidase inhibitor O-(2-acetamido-2deoxy-D-glucopyranosylidene) amino-N-phenylcarbamate. J Biol Chem 273: 3611-3617

22. Haltiwanger RS, Blomberg MA, Hart GW (1992) Glycosylation of nuclear and cytoplasmic proteins. J Biol Chem 267: 9005-9013

23. Hart GW (1997) Dynamic O-linked glycosylation of nuclear and cytoplasmic proteins. Annu Rev Biochem 66: 315-335 
24. Buchanan KD, Mawhinney WA (1973) Glucagon release from isolated pancreas in streptozotocin-treated rats. Diabetes 22: 797-800

25. Malaisse WJ, Malaisse-Lagae F, Van Obberghen E et al. (1975) Role of microtubules in the phasic pattern of insulin release. Ann NY Acad Sci 253: 630-652

26. Suprenant KA, Dentler WL (1982) Association between endocrine pancreatic secretory granules and in-vitroassembled microtubules is dependent upon microtubulesassociated proteins. J Cell Biol 93: 164-174

27. Howell SL, Tyhurst M (1986) The cytoskeleton and insulin secretion. Diabetes Metab Rev 2: 107-123

28. Pelham HR, Munro S (1993) Sorting of membrane proteins in the secretory pathway. Cell 75: 603-605

29. Chilcote T J, Siow YL, Schaeffer E, Greengard P, Thiel G (1994) Synapsin IIa bundles actin filaments. J Neurochem 63: $1568-1571$

30. Chou C-F, Smith AJ, Omary, MB (1992) Characterization and dynamics of O-linked glycosylation of human cytokeratin 8 and 18. J Biol Chem 267: 3901-3906

31. Arnold CS, Johnson VW, Cole RN, Dong DL-Y, Lee M, Hart GW (1996) The microtubule-associated protein tau is extensively modified with O-linked N-acetylglucosamine. J Biol Chem 271: 28741-28744

32. Ding M, Vandre DD (1996) High molecular weight microtubule-associated proteins contain O-linked-N-acetylglucosamine. J Biol Chem 271: 12555-12561

33. Cole RN, Hart GW (1999) Glycosylation sites flank phosphorylation sites on synapsin I: O-linked N-acetylglucosamine residues are localized with domains mediating synapsin I interactions. J Neurochem 73: 418-429

34. Traxinger RR, Marshall S (1991) Coordinated regulation of glutamine: fructose-6-phosphate amidotransferase activity by insulin, glucose, and glutamine. Role of hexosamine biosynthesis in enzyme regulation. J Biol Chem 266: 10148-10154

35. Hebert LF, Daniels MC, Zhou J et al. (1996) Overexpression of glutamine: fructase-6-phosphate amidotransferase in transgenic mice leads to insulin resistance. J Clin Invest 98: 930-936

36. Cooksey RC, Hebert LF, Zhu J-H, Wofford P, Garvey WT, McClain DA (1999) Mec hanism of Hexosamine-induced insulin resistance in transgenic mice overexpressing Glutamine: Fructose-6-phosphae amidotransferase: decreased glucose transporter GLUT4 translocation and reversal by treatment with thiazolidinedione. Endocrinology 140: $1151-1157$

37. Weis RB (1982) Streptozotocin: a review of its pharmacology, efficacy and toxicity. Cancer Treat Res 66: 427-438

38. Wilson GL, Leiter EH (1990) Streptozotocin interactions with pancreatic beta cells and the induction of insulin-dependent diabetes. Curr Topics Microbiol Immunol 156: 27-54

39. Like AA, Appel MC, Williams RM, Rossini AA (1978) Streptozotocin-induced pancreatic insulitis in mice. Morphologic and physiologic studies. Lab Invest 38: 470-486
40. Kolb-Bachofen V, Epstein S, Kiesel U, Kolb H (1988) Lowdose streptozotocin-induced diabetes in mice. Electron microscopy reveals single-cell insulitis before diabetes onset. Diabetes 37: 21-27

41. Richens ER, Tungekar FM, Behbehani K (1988) A longitudinal ultrastructural study of pancreatic cellular damage in murine streptozotocin diabetes. Acta Diabetol 25: 185-195

42. Hamming NA, Reynold WA (1977) DNA synthesis in pancreatic islet and acinar cells in rats with streptozotecininduced diabetes. Horm Metab Res 9: 114-116

43. Schnedl WJ, Ferber S, Johnson JH, Newgard CB (1994) STZ transport and cytotoxicity. Specific enhancement in GLUT2-expressing cells. Diabetes 43: 1326-1333

44. Takata K, Hirano H, Kasahara M (1997) Transport of glucose across the blood-tissue barriers. Int Rev Cytol 172: $1-53$

45. Yamamoto H, Uchigata Y, Okamoto H (1981) Streptozotocin and alloxan induce DNA strand breaks and poly (ADPribose) synthetase in pancreatic islets. Nature 294: 284-286

46. Turk J, Corbett JA, Ramanadham S, Bohrer A, McDaniel ML (1993) Biochemical evidence for nitric oxide formation from streptozotocin in isolated pancreatic islets. Biochem Biophys Res Commun 197: 1458-1464

47. Kaneto H, Fujii J, Seo HG et al. (1995) Apoptic cell death triggered by nitric oxide in pancreatic $\beta$-cells. Diabetes 44 : 733-739

48. Melino G, Bernassola F, Knight RA, Corasaniti MT, Nistico G, Finazzi-Agro A (1997) S-nitrosylation regulates apoptosis. Nature 388: 432-433

49. Ledoux SP, Woodley SE, Patton NJ, Wilson GL (1986) Mechanisms of nitrosourea-induced beta-cell damage. Alterations in DNA. Diabetes 35: 866-872

50. Flament P, Remacle C (1987) Ultrastructural aspects of streptozotocin cytotoxicity on rat pancreatic islets in vitro. Test of a protective effect of zinc. Virchows Arch 53: 107-112

51. Kwon NS, Lee SH, Choi CS, Kho T, Lee HS (1994) Nitric oxide generation from streptozotocin. FASEB J 8: 529-533

52. Radons J, Heller B, Bürkle A et al. (1994) Nitric oxide toxicity in islet cells involves poly (ADP-ribose) polymerase activation and concomitant NAD + depletion. Biochem Biophys Res Commun 199: 1270-1277

53. Roos MD, Xie W, Su K et al. (1998) Streptozotocin, an analog of $\mathrm{N}$-acetylglucosamine, blocks the removal of O-GlcNAc from intracellular proteins. Proc Assoc Am Physicians 110: 422-432

54. Hanover JA, Lai Z, Lee G, Lubas WA, Sato SM (1999): Elevated O-linked N- $\beta$-Acetylglucosamine metabolism in pancreatic B-cells. Arch Biochem Biophys 362: 38-45

55. Konrad RJ, Janowski KM, Kudlow JE (2000) Glucose and streptozotocin stimulate $135 \mathrm{O}$-glysosylation in pancreatic islets. Biochem Biophys Res Commun 267: 26-32

56. Liu K, Paterson AJ, Chin E, Kudlow JE (2000) Glucose stimulates protein modification by O-linked GlcNAc in pancreatic beta cells: linkage of O-linked GlcNAc to beta cell death. Proc Natl Acad Sci USA 97: 2820-2825 